\title{
Innovations that changed mammalogy: the Cyclone trap
}

\author{
Hugh H. Genoways, Suzanne B. McLaren, and Robert M. Timm* \\ University of Nebraska State Museum, University of Nebraska-Lincoln, Lincoln, NE 68588, USA (HHG) \\ Section of Mammals, Edward O'Neil Research Center, Carnegie, Museum of Natural History, Pittsburgh, PA 15206, USA (SBM) \\ Department of Ecology \& Evolutionary Biology and Biodiversity Institute, University of Kansas, Lawrence, KS 66045, USA \\ $(R M T)$ \\ *Correspondent: btimm@ku.edu
}

To celebrate the 100th Annual Meeting of the American Society of Mammalogists (ASM), we plan a series of five brief articles looking at innovations that changed how we practice the science of mammalogy. One of these was the result of an invention, others involved repurposing of objects, and still others took techniques from the laboratory and transplanted them into the field. We hope these contributions will give ASM members a deeper appreciation of the development of our profession as we enter a second century of research and publishing. Our first selection for an innovation that changed mammalogy is the invention of the Cyclone trap (Fig. 1).

Building a better mousetrap long has been an obsession with humans, and mammalogists continue to tinker with obtaining that perfect trap and the most effective bait (Woodman et al. 1996). The Cyclone trap was invented by two brothers, John and Thomas Morris, of Seward, Nebraska, in 1883 (Morris and Morris 1883). The Morris brothers placed their invention in "that class of traps known as 'dead-fall traps'," which allowed the animal to approach the bait from all directions and be caught. The brothers patented their trap simply as "animal trap," being careful to not specify what animals were to be caught so as not to restrict future marketing. "This trap, called the Cyclone, was an affair of tin and wire springs, only about two inches square when collapsed, cheap in cost, and easily portable in quantity" (Osgood 1944:9). There were four Morris brothers living in the Seward area and from 1867 to 1908; they patented 35 different traps and other devices. Of these patents, nine were for animal traps or improvements to animal traps (Drummond 1997). Their most famous trap, still available on the market today, was the Delusion, invented by John in 1877. This was a multi-capture, non-folding metal box live trap that employed a trap door mechanism to hold more than one individual at a time (Morris 1877).

The Cyclone trap came to market in the mid-1880s, at the same time as C. Hart Merriam was tiring of his medical practice and had finished his early study of mammals, Mammals of the Adirondacks (Merriam 1884). Merriam was heavily engaged in work on birds when he was appointed in 1885 as chief of the federal bureau that eventually evolved into the U.S. Biological Survey (Storer 1969). Gerritt S. Miller, Jr. (1929:406) described the impact of the Cyclone trap on Merriam's career: "Armed with an effective trap he was able to apply to the investigation of mammals the principles which he learned from the study of birds, the salient features of which are the bringing together and minute comparative study of large series of specimens - all uniformly prepared-from every possible locality. Had this not happened at this particular time, the recent history of mammalogy would have been different throughout the world." As Tracy Storer (1969:786) pointed out: "The resulting series of specimens made it possible to differentiate sex, age, and geographic variations." An early example of the impact of this collecting on research was "Wilfred Osgood's 1909 monograph of 285 pages on the genus Peromyscus ... in which 27,000 specimens were used."

Miller (1929:406) gave a very clear description of his first experience with the Cyclone trap:

I remember my own first attempts at field work, when the only traps to be had were clumsy wooden objects stained bright red and shaped like a round of flat cheese with the side bored full of holes through which the victims were expected to thrust their heads in order to be choked. Not ineffective for house mice, these traps became exasperating failures when carried to the fields and woods. A summer's industrious work with them failed to procure me a single individual of the short-tailed shrew or redbacked mouse, two of the common mammals in the woods near my home. Then came word of the new technique and with it six dozen "Cyclone" traps. Immediately I was able to get all the specimens that I could prepare.

Although Miller's initial impression of the Cyclone trap was highly favorable, he was by 1901 registering this complaint:

(C) 2020 American Society of Mammalogists, www.mammalogy.org 


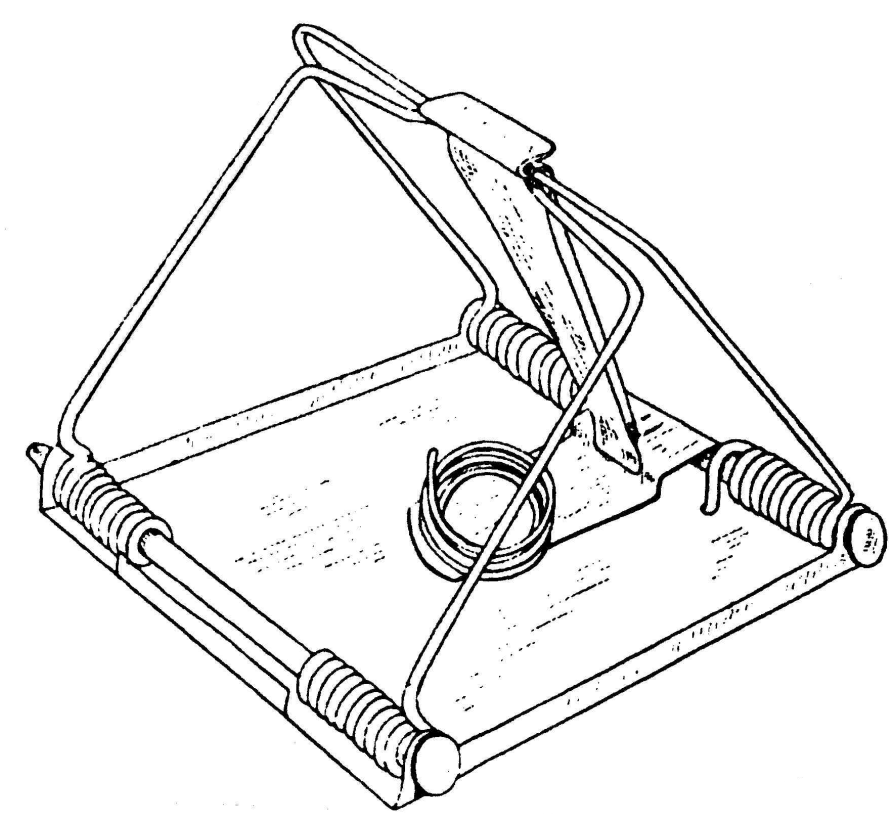

Fig. 1. - The Cyclone trap set and ready for action. The name comes from the coiled springs that resemble a cyclone. The base of the trap measures $23 / 8$ by 2 1/16 inches. Redrawn from Miller (1901:24).

"Its chief disadvantage lies in the tin base, which readily becomes rusty, and in this condition causes much staining of specimens" (Miller 1901:23). At this time Cyclone traps were being produced by the Lovell Manufacturing Company of Erie, Pennsylvania. Miller (1901) recommended two other acceptable traps - the Out o' sight trap from the Animal Trap Company of Abington, Illinois, and the Schuyler trap from J. R. Schuyler Co. of Bloomsburg, Pennsylvania. The Out o' sight trap had a wooden base and the Schuyler trap was made of galvanized steel; both thus avoided the problem of the Cyclone trap. Most mammalogists would recognize the Out o' sight trap because in a later iteration of the proper size, this trap would become known as the Museum Special trap. The wooden base of this trap often did not hold up to wet weather, but soaking in raw linseed oil provides waterproofing, and coating with a thin layer of melted paraffin particularly effective in deterring termites.

The Out o' sight trap was invented by William Hooker of Abington, Illinois, in 1894 (Hooker 1894). It was a "break-back type trap" being a spring or snap trap. The power of the trap came from a single piece of wire coiled to form a transverse spring to close the jaw. The Museum Special version of this trap was sized so that the kill bar was further from the bait pan than in other small mouse traps so that the trap did indeed break the back of the mouse rather than crushing the back of the cranium; it came into widespread use in mammalogy in the late 1930s (Hatfield 1938).

In more recent years, when live animals were desired for karyotyping, collecting of fresh tissues, and behavioral studies, the Sherman trap has been the go-to choice for many mammalogists. These traps were invented by H. B. Sherman in the 1920s, but only became available in quantity after his retirement from the University of Florida in 1955 (Sherman Phillips 2015). Sherman traps come in various sizes and construction materials, including aluminum, galvanized steel, and combinations of the two. The most commonly used of these traps is the "Rodent/Rat/Mouse Trap" ( 3 by 3.5 by 9 inches) folding aluminum trap. They are light enough that most researchers are able to carry 40 to 50 in setting a trapline. The traps are easily opened for cleaning and repair and spare parts can be purchased and installed even by a mammalogist.

Numerous types of specialized traps have been invented over the years to trap species occupying unique habitats, such as fossorial mammals. Among these types of traps are the Victor plunger style mole trap and the Macabee pocket gopher trap, with many variations of both types. When the necessity arose for live traps for such species, mammalogists have risen to the challenge, creating a modified plunger style mole trap mounted over a metal box that protects and keeps the mole alive (Yates and Schmidly 1977). Baker and Williams (1972) created a live trap for pocket gophers out of PVC pipe, a door hinge, and a Victor rat trap as the triggering mechanism.

Thousands of years of ingenuity have gone into trapping mammals (Fitzwater 1970), but with industrialization came such innovations as the Cyclone trap in 1883, a specialized, commercially available, and effective trap for mammalogists to obtain museum quality specimens. As we have entered 2020 and are heading toward the end of the first quarter of the $21 \mathrm{st}$ century, fieldwork and the trapping of mammals is less prevalent than in the past. This is occurring because of increased regulations involving the use of animals in research and teaching; declining funding for fieldwork-type studies; and declining mammal populations due to habitat loss and climate change. However, those mammalogists conducting biodiversity surveys, studies of genomics, and related studies continue to find a need for additional wild-taken individuals. Mammalogists today have a wide array of specialized traps available to them that in many ways are the cultural legacy of nearly 140 years of ingenuity and innovation beginning in 1883 with the Cyclone.

\section{ACKNOWLEDGMENTS}

E. J. Heske and L. A. Ruedas critically reviewed an earlier draft of this manuscript, considerably improving it.

\section{Literature Cited}

BAKer, R. J., AND S. L. Williams. 1972. A live-trap for pocket gophers. Journal of Wildlife Management 36:1320-1322.

Drummond, D. 1997. "The Delusion" of John Morris: a better mouse trap and its makers. Nebraska History 78:64-74.

FitzWateR, W. D. 1970. Trapping-the oldest profession. Proceedings of the Vertebrate Pest Conference 4:101-108.

Hatfield, D. M. 1938. Studies on rodent populations in a forest area. Journal of Mammalogy 19:207-211.

Hooker, W. C. 1894. United States Patent No. 528,671. https:// patents.google.com/patent/US528671A/en?oq=US528\%2c671. Accessed 7 November 2019.

Merriam, C. H. 1884. The mammals of the Adirondack Region, northeastern New York. Privately published by the author with L. S. Foster, New York. 
Miller, G. S., JR. 1901. Directions for preparing study specimens of small mammals. 2nd ed. Bulletin of the United States National Museum 39:1-25.

Miller, G. S., JR. 1929. Mammalogy and the Smithsonian Institution. The Smithsonian Report for 1928, pp. 391-411.

MorRIs, J. H. 1877. United States Patent No. 195,632. https://patents. google.com/patent/US195632A/en. Accessed 7 November 2019.

Morris, J. H., AND T. D. Morris. 1883. United States Patent No. 288,182. https://patents.google.com/patent/US288182A/en?oq= US288182. Accessed 7 November 2019.

OsGood, W. H. 1909. Revision of mice of the American genus Peromyscus. North American Fauna 28:1-283.

Osgood, W. H. 1944. Biographical memoir of Clinton Hart Merriam 1855-1942. Biographical Memoirs, National Academy of Sciences of the United States of America 24:1-29.
Sherman Phillips, C. L. 2015. The Sherman trap tradition. https:// www.shermantraps.com. Accessed 8 November 2019.

Storer, T. I. 1969. Mammalogy and the American Society of Mammalogists, 1919-1969. Journal of Mammalogy 50:785-793.

Woodman, N., R. M. Timm, N. A. Slade, and T. J. Doonan. 1996. Comparison of traps and baits for censusing small mammals in Neotropical lowlands. Journal of Mammalogy 77:274-281.

Yates, T. L., AND D. J. Schmidly. 1977. Systematics of the eastern mole Scalopus aquaticus (Linnaeus) in Texas and adjacent states. Occasional Papers of the Museum, Texas Tech University 45:1-36.

Submitted 7 January 2020. Accepted 7 February 2020.

Associate Editor was Luis A. Ruedas. 